\title{
FMTLxLyLz DIMENSIONAL EQUATION FOR SLUDGE DRYING BEDS
}

\author{
J. 0. Ademiluyi ${ }^{1}$ and B. I. Eze ${ }^{2, *}$

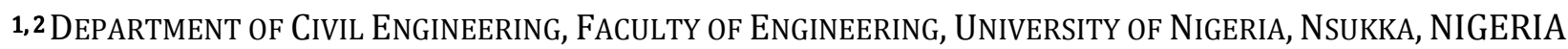 \\ Email addresses: ${ }^{1}$ doyenacademy@yahoo.com, 2 ifeanyiezeus@yahoo.com
}

\begin{abstract}
An equation for sludge dewatering using $F M T L_{x} L_{y} L_{z}$ dimensional analysis approach has been presented. A pilot plant made of $12 \mathrm{~mm}$ thick steel plate was used in designing a drying bed, $1.20 \mathrm{~m}$ long, $0.75 \mathrm{~m}$ wide, $0.80 \mathrm{~m}$ deep with a total area of $0.90 \mathrm{~m}^{2}$ and was used in dewatering sewage sludge from the University of Nigeria, Nsukka, waste water treatment plant. Parameters affecting filtration processes were used to derive an equation using dimensional analysis approach. The derived equation based on the concept of specific resistance, was used to investigate the performance of the sand drying bed as a sludge dewatering option. On verification using the experimental data obtained from the sewage plant, the theoretical prediction of the derived equation gave a close relationship to the practical values with a correlation of 0.994. The specific resistance from the experimental data was found to increase as the hydrostatic pressure increases numerically. Also, when ferric chloride was used to verify the effect of chemical conditioner on the sludge, it was observed that the specific resistance decreases with increasing dosage of chemical with the following results: Dosage increase of $10 \mathrm{~g}, 20 \mathrm{~g}, 30 \mathrm{~g}, 40 \mathrm{~g}$ and $50 \mathrm{~g}$ of ferric chloride gave specific resistance decrease of $1.2271 \times 10^{8} \mathrm{~m} / \mathrm{kg}, 0.4998 \times 10^{8} \mathrm{~m} / \mathrm{kg}, 0.29803 \times 10^{8} \mathrm{~m} / \mathrm{kg}, 0.18124 \times 10^{8} \mathrm{~m} / \mathrm{kg}, 0.075466 \times$ $10^{8} \mathrm{~m} / \mathrm{kg}$ respectively. Equally, when the effect of dilution was investigated, the specific resistance showed a decrease in value with increasing initial solid content. The experimental results obtained were in accordance with earlier studies done by other researchers.
\end{abstract}

Keywords: sludge dewatering, sand drying bed, dimensional analysis, specific resistance, chemical conditioner

\section{INTRODUCTION}

Waste generation is a growing problem facing the world and this is as a result of rapid industrialization, urbanization and expansion in population growth. Emphasis on agriculture for more food production to take care of the astronomical increase in population has generated increased volume of domestic industrial as well as agricultural wastes.

Owing to health and other environmental hazards like water, air and soil pollution, posed by industrial, domestic and agricultural wastewaters to the existence of man and the entire ecosystem there is therefore every need to treat wastewater properly before discharging them to the receiving streams, water bodies or agricultural lands.

According to [1], sludge, a term used to designate the solid that settles when sewage is passed through a settling tank is a serious problem to all wastewater treatment plants worldwide in terms of disposal, transportation and handling. Wastewater processing plants in an effort to meet more stringent discharge measures and limitations led to increased volume of sludge production. Sludge dewatering is a wastewater treatment process that reduces the water content of the sludge so that it can be transported, handled and disposed with ease. In most dewatering process the ability of sludge to form and maintain a porous media that enhances its compressibility is a desired goal [2]. Dewatering and disposal of sludge is a major economical factor in the operation of wastewater treatment plant, [3] reported that 30- 50\% of the annual operating costs of treatment plants are related to sludge dewatering alone.

So many techniques exist for dewatering sludge and these include mechanical method as well as natural method. Natural filtration methods include the drying bed, lagoons, oxidation ditch etc.

Sand drying bed is a natural dewatering technique that makes use of natural phenomenon such as losing water to the atmosphere by evaporation and also percolation through the filter medium via an under drain to achieve sludge volume reduction. It is more 
economical to operate and maintain when compared to mechanical means, though large area of land is required. Drying beds are mostly used in small industries as well as small communities with populations of over 100,000 people [4]. Dispersed particles in sludge has often been observed to have a negative effects on filtration rate and the increase in resistance experienced using drying bed is due to the blinding of the filter medium of sludge cake with small particles [5]. Drying time depends on weather or climatic conditions and equally on the thickness of the sludge applied. It may vary from 10 days to several weeks. For efficient performance during rainy season, drying beds may be provided with covers to avoid interference from weather and climatic conditions (rainfall, humidity etc.). The objective of this research work is to use dimensional analysis method Force, mass, time in three dimensions $\left(\mathrm{FMTL}_{x} \mathrm{~L}_{y} \mathrm{~L}_{z}\right)$ to develop sludge filtration equation without the compressibility attribute and also to examine the effect of conditioner on specific resistance using drying bed.

Dimensional analysis according to [6] is a mathematical technique which makes use of the study of the dimensions for solving engineering problem. It is an important tool for analyzing fluid flow problems.

Dewatering process helps to remove high water content such that the sludge can be handled and transported easily over a long distance for ultimate disposal and in effect reduces cost. The raw sludge has about $97.5 \%$ water content and $2.5 \%$ solid [7]. Dewatering process increases solid content between 20 to $35 \%$ [8].

Over the years researchers in this field have come up with many theories and derived equations based on experimental assumptions and conditions, [9] proposed an equation for sludge dewatering at constant vacuum pressure as;

$$
\begin{gathered}
V^{2}=\frac{P A^{2} t}{\mu c r} \\
r=r^{1} P^{s}
\end{gathered}
$$

In (1) and (2), $\mathrm{V}$ is the volume of filtration $\left(\mathrm{m}^{3}\right), \mathrm{c}$ is the solid concentration $\left(\mathrm{Kg} / \mathrm{m}^{3}\right), \mathrm{P}$ is the filtration pressure $\left(\mathrm{N} / \mathrm{m}^{2}\right), r$ is the specific resistance $(\mathrm{m} / \mathrm{Kg}), A$ is the area of filtration $\left(\mathrm{m}^{2}\right), \mu$ is the dynamic viscosity $\left(\mathrm{N} . \mathrm{s} / \mathrm{m}^{2}\right), \mathrm{t}$ is the time of filtration (s) and $\mathrm{s}$ is the compressibility coefficient $\left(\mathrm{m}^{2} / \mathrm{N}\right)$.

The work done by Carman on filtration was based on the idea of specific resistance and the velocity time plot at constant pressure and on ideal situation where the cake formed is considered rigid at constant pressure. He was of the idea that specific resistance is independent of solid concentration and opined that the total loss of pressure arises from, pressure drop across filter cake, pressure drop across initial resistance, and loss incurred in filtrate recovery. The cake formed during filtration process shows that the cake so formed does not change volume as pressure builds up and for non rigid cake the pressure across the cake increases faster than the cake build up [10]. Equally [11] showed that Carman's equation does not give room for low compressibility value to be evaluated with any degree of accuracy and for a rigid cake, the compressibility coefficient $S_{c}=0$ and that low compressibility is equal to unity and proposed an equation of the form;

$$
r=r_{1}\left(1+r_{2} P S_{c}\right)
$$

where $r_{1}$ and $r_{2}$ are constants, $r$ is the specific resistance, $\mathrm{P}$ is the filtration pressure and $\mathrm{S}_{\mathrm{c}}$ is the compressibility coefficient.

Carman's equation was later developed by [12] and showed that the rate of filtration is given by,

$$
\frac{d V}{d t}=\frac{P A^{2}}{\mu\left(\alpha c+R_{m} A\right)}
$$

where $\alpha$ and $R_{m}$ are the specific resistance of cake and that of the filter medium respectively. After integrating, equation (4) turns out a straight line when $\mathrm{t} / \mathrm{V}$ is plotted against $\mathrm{V}$, with a slope $=\frac{\mu \alpha c}{2 P A^{2}}$ and intercept $=\frac{R_{m} \mu}{P A}$.

Another researcher [13] also criticized the work done by [9] on the assumption he made that the cake formed during filtration process is rigid as compared with sand bed which he assumed as bundle of capillary tubes. He used dimensional analysis to formulate filtration equation based on force, mass, time in three dimensions, the variables that have significant effect on sludge filtration are reduced to the fundamental quantity of force, mass, time and length. Length is further divided into three, $\mathrm{x}, \mathrm{y}, \mathrm{z}$ representing the three mutual axis in space. He opined that the major factors that could affect filtration process include, pressure, Area of filtration, time, specific resistance, concentration of solids, dynamic viscosity and gave an equation of the form;

$$
V^{2}=\frac{P A^{5 / 2} t}{\mu c^{1 / 2} r^{1 / 2}}
$$

But [14], objected to the use of FMTL $L_{x} L_{y} L_{z}$ saying that mass and force can both be used as fundamentals only in the unusual situations when the physical proportionality between the two is not involved in any 
of the terms and suggested that, the partial equation developed by [13] be written thus,

$$
V^{2}=P \mu^{-1} A^{2 b} t(c r)^{2 b-3}
$$

In (6), $t$ is the time of filtration, $r$ is the specific resistance, $A$ is the area of filtration, $v$ is the volume of filtration, $\mathrm{p}$ is the filtration pressure, $\mathrm{c}$ is the concentration of solid and $\mu$ is the dynamic viscosity They finally agreed that the correct determination of the exponent $b$, based on theoretical or experimental consideration would guide the choice of filtration equation. Much later [7] worked relentlessly to determine experimentally the value of the exponent $b$, using Buchner funnel technique as described by [12], they stated that,

$$
V^{2}=\frac{P A_{t}^{1.82} t}{\mu(c r)^{1.18}}
$$

And

$$
V^{2}=\frac{P A_{e f f}^{2.76} t}{\mu(c r)^{0.24}}
$$

where $A_{t}$ and $A_{\text {eff }}$ are total and effective area of the Buchner funnel respectively. Also in another development [13] proposed another filtration equation known as sludge dewaterability number SDN and discovered that sludge filtration parameter is dependent not only on the equipment design but also on pre- treatment before dewatering and other unquantifiable physical factors such as ageing, shear to the filter medium, etc and stated that,

$$
S D N=\frac{\Delta H\left(c_{0}-c_{f}\right)}{V_{i} c_{c} t}+\frac{H_{0}}{V_{i} t}
$$

In (9) where $C_{0}$ is the initial concentration of sludge $\left(\mathrm{Kg} / \mathrm{m}_{3}\right), \Delta H$ is the change in head loss $(\mathrm{m}), \mathrm{C}_{\mathrm{f}}$ is the filtration concentration $\left(\mathrm{Kg} / \mathrm{m}^{3}\right), C_{c}$ is the cake concentration $\left(\mathrm{Kg} / \mathrm{m}^{3}\right), \quad H_{0}$ is the initial head loss $(\mathrm{m}), \mathrm{V}_{\mathrm{i}}$ is the approach velocity $(\mathrm{m} / \mathrm{s})$.

\section{EXPERIMENTAL SET-UP AND METHODS OF ANALYSIS.}

The pilot plant as shown below is made of $12 \mathrm{~mm}$ thick steel plate. Its dimension is $1.2 \mathrm{~m}$ long, $0.75 \mathrm{~m}$ wide, $0.80 \mathrm{~m}$ deep and a total filtration area of $0.9 \mathrm{~m}^{2}$. At the top of the perforated base, is $200 \mathrm{~mm}$ course of gravel followed by $200 \mathrm{~mm}$ course of fine sand, $250 \mathrm{~mm}$ thick sludge. The set up was used to dewater sewage sludge collected from the wastewater treatment plant (Imhoff tank) at the University of Nigeria, Nsukka. The experiment started by collecting and pouring sewage sludge into the drying bed to a height of $250 \mathrm{~mm}$. Filtrate from the sludge started percolating through the sand bed by gravitational movement of water downwards. Water was also lost by evaporation from the surface of the sludge, readings were taken and specific resistance was calculated using the derived equation. Thermometers were inserted at the four corners of the sand drying bed to measure the difference in sludge temperatures and the atmospheric temperatures. Measurements were taken at interval of two hours on the first day and 24 hours on the subsequent days. Effects of chemical conditioner and also dilution, on the specific resistance of the sludge were also investigated using the same set up.

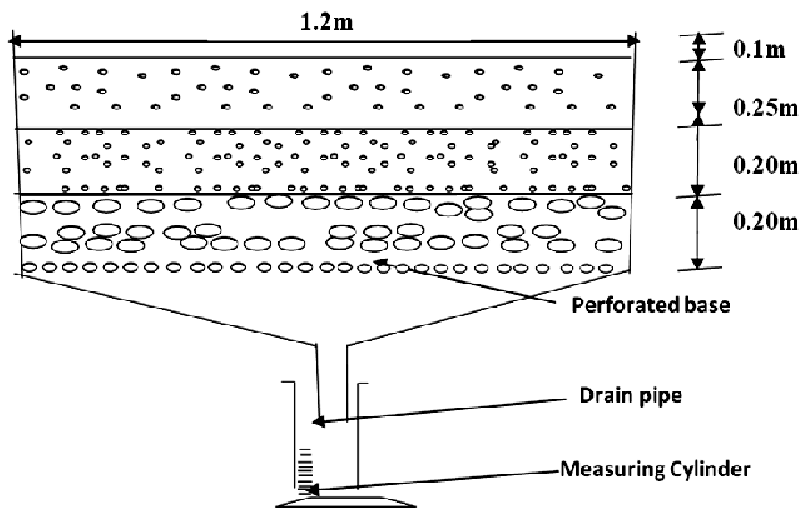

Figure 1: Schematic diagram of sand drying bed.

\section{DERIVATION OF SLUDGE FILTRATION EQUATION USING FMTL $L_{x} L_{y} L_{z}$ DIMENSIONAL ANALYSIS METHOD.}

Since no chemical reaction is assumed to take place during sludge filtration, the process can be assumed to constitute a physical system and dimensional analysis can be used in deriving an equation to describe the system.

However, in deriving the equation only the effective terms are incorporated.

Table 1: FMTL Dimensions.

\begin{tabular}{lcc}
\hline Physical variables & Symbols & $\begin{array}{c}\text { Fundamental } \\
\text { systems } \\
\left(F M T L_{x} L_{y} L_{z}\right)\end{array}$ \\
\hline $\begin{array}{l}\text { Volume of filtration } \\
\left(\mathrm{m}^{3}\right)\end{array}$ & $\mathrm{V}$ & $L_{x} L_{y} L_{z}$ \\
$\begin{array}{l}\text { Filtration Area }\left(\mathrm{m}^{2}\right) \\
\begin{array}{l}\text { Filtration Time (s) } \\
\text { Mass of dry cake per }\end{array}\end{array}$ & $\mathrm{A}$ & $L_{x} L_{y}$ \\
$\begin{array}{l}\text { unit volume }\left(\mathrm{Kg} / \mathrm{m}^{3}\right) \\
\text { Net filtration } \\
\text { pressure }\left(\mathrm{N} / \mathrm{m}^{2}\right)\end{array}$ & $\mathrm{C}$ & $\mathrm{M} L_{x}^{-1} L_{y}^{-1} L_{z}^{-1}$ \\
$\begin{array}{l}\text { Viscosity of } \\
\text { filtration }\left(\mathrm{N} . \mathrm{S} / \mathrm{m}^{2}\right)\end{array}$ & $\mathrm{P}$ & $\mathrm{F} L_{x}^{-1} L_{y}^{-1}$ \\
$\begin{array}{l}\text { Specific } \\
\text { resistance }(\mathrm{m} / \mathrm{Kg})\end{array}$ & $\mathrm{R}$ & $\mathrm{FT} L_{z}^{-1}$ \\
\hline
\end{tabular}

$$
V=P^{a} A^{b} C^{c} \mu^{d} R^{e} t^{f}
$$


Applying dimension;

$$
\begin{array}{r}
L_{x} L_{y} L_{z}=\left(F L_{x}^{-1} L_{y}^{-1}\right)^{a} \times\left(L_{x} L_{y}\right)^{b} \times\left(M L_{x}^{-1} L_{y}^{-1} L_{z}^{-1}\right)^{c} \\
\times\left(F T L_{z}^{-2}\right)^{d} \times\left(M^{-1} L_{z}\right)^{e} \times(T)^{f}
\end{array}
$$

Solving we obtain;

$$
\begin{aligned}
& V=\left(\frac{P t}{\mu}\right)^{1 / 2} A^{3 / 2} A^{e} C^{e} R^{e} \\
& V=\left(\frac{P t}{\mu}\right)^{1 / 2} A^{3 / 2}(A C R)^{e} \\
& V=\left(\frac{P t A^{2}}{\mu}\right)^{\frac{1}{2}}(A C R)^{e} \\
& V=t^{1 / 2}\left(\frac{P A^{2}}{\mu}\right)^{1 / 2}(A C R)^{e} \\
& \frac{V}{t^{\frac{1}{2}}}=\left(\frac{P A^{2}}{\mu}\right)^{\frac{1}{2}}(A C R)^{e} \\
& \frac{t^{1 / 2}}{V}=\left(\frac{P A^{2}}{\mu}\right)^{1 / 2}(A C R)^{e}
\end{aligned}
$$

$$
\text { Solving; }
$$

$$
\frac{t}{V^{2}}=\left(\frac{P A^{2}}{\mu}\right)^{-1}(A C R)^{-2 e}
$$

$\frac{t}{V}=V\left(\frac{\mu}{P A^{2}}\right)(A C R)^{-2 e}$

If $\mathrm{t} / \mathrm{V}$ is plotted against solid content $\mathrm{C}$, it gives a straight line showing, that the volume of filtrate is proportional to the solid content.

Equating the powers we have, $-2 \mathrm{e}=1$ or e $=-1 / 2$. Substituting $e=-1 / 2$ in equation (18),

$$
\begin{aligned}
& \frac{t}{V}=V=V\left(\frac{\mu}{P A^{2}}\right)(A C R)^{-2 X-\frac{1}{2}} \\
& \therefore \frac{t}{V}=V\left(\frac{\mu C R}{P A^{2}}\right)
\end{aligned}
$$

But,

$$
\frac{t}{V}=f\left(\frac{V \mu C R}{P A^{2}}\right)
$$

By observing the experimental plot of $t / \mathrm{V}$ versus $\mathrm{V}$, equation (21) should be re - written as,

$$
\frac{t}{V}=V\left(\frac{\mu C R}{P A^{2}}\right)+\beta
$$

where $\quad \beta$ is the intercept of the plot of $\frac{t}{V}$ against $\mathrm{V}$. Since we are working on natural drying bed, the pressure $\mathrm{P}$, under consideration is hydrostatic, i.e. $\mathrm{P}$ $=\rho g h$. Applying $\mathrm{P}=\rho g h$ in equation (20) we obtain,

$$
\frac{t}{V}=V\left(\frac{\mu C R}{\rho g h A^{2}}\right)+\beta
$$

Also

$$
C=\frac{w_{d}}{v_{s}}, \quad \therefore \frac{t}{V}=V\left(\frac{\mu R w_{d}}{\rho g h A^{2} V_{s}}\right)+\beta
$$

If $\frac{t}{V}$ is plotted against $\mathrm{V}$, the slope say $\mathrm{b}$ of the straight line is given by:

$$
b=\frac{\mu R w_{d}}{\rho g h A^{2} V_{s}}
$$

Specific resistance $\mathrm{R}$, is calculated thus,

$$
R=b\left(\frac{\rho g h A^{2} V_{s}}{\mu w_{d}}\right)
$$

In (26), $\mathrm{R}$ is the specific resistance $(\mathrm{m} / \mathrm{kg}), \mathrm{A}$ is the area of filtration $\left(\mathrm{m}^{2}\right), \mathrm{b}$ is the Slope $\left(\mathrm{s} / \mathrm{m}^{6}\right), \mathrm{C}$ is the solid content $\left(\mathrm{kg} / \mathrm{m}^{3}\right), \mu$ is the dynamic viscosity $\left(\mathrm{N} . \mathrm{s} / \mathrm{m}^{2}\right), \quad V_{s}$ is the volume of sludge $\left(\mathrm{m}^{3}\right), w_{d}$ is the weight of dry sludge $(\mathrm{kg})$ and $\rho g h$ is the hydrostatic pressure $\left(\mathrm{N} / \mathrm{m}^{2}\right)$.

\section{RESULTS AND DISSCUSIONS}

As the filtration process began, it was observed that the filtrate was high and clear on day one and this may be attributed to low resistance offered by the filter septum (the sand bed) alone. As the filtration proceeds, the thickness of the cake keeps building up and as a result there is a reduction in the volume of filtrate and this is due to the combined effect of the resistance offered by the filter septum and the cake formed. Before now, most of the dewatering process is by drainage through the sand bed. As the sludge height decreases, there is a corresponding increase in the hydrostatic pressure.

The plot of $t / v$ against $V$ gave a straight line and the specific resistance increases as the pressure increases. The efficiency of the drying bed was also investigated by plotting a graph of $\mathrm{t} / \mathrm{V}$ against hydrostatic pressure versus time, this gave a straight line. Investigating the effect of dilution on the specific resistance, each sludge volume was diluted to varying concentration using different dosage of distilled water, dilution was done within comparable range and it shows that the resistance decreases as the dosage of the distilled water increases. As dilution increases more fines attain their 'disintegration energy' and therefore increase the filter medium blinding.

Effect of ferric chloride was investigated and each sludge volume was conditioned using different dosage of ferric chloride $\left(\mathrm{Fecl}_{3}\right)$ 10g, 20g, 30g, 40g, and 50g and their corresponding specific resistance are, $1.2271 \times 10^{8} \mathrm{~m} / \mathrm{Kg}, 0.4998 \times 10^{8} \mathrm{~m} / \mathrm{Kg}, 0.29803 \times$ $10^{8} \mathrm{~m} / \mathrm{Kg}, 0.18124 \times 10^{8} \mathrm{~m} / \mathrm{Kg}, 0.07545 \times 10 \mathrm{~m} / \mathrm{Kg}$ respectively. The result from the experimental data analysis shows that the specific resistance decreases with increasing dosage of ferric chloride. The effectiveness of ferric chloride conditioner in lowering the specific resistance of the sludge in this study was 
due to coagulation of fine particles in the sludge, larger particles are gathered together by the sludge and hence they become more porous. The result shows that the derived equation is valid and can be adopted for sludge dewatering.

The data and graph analysis are as shown;

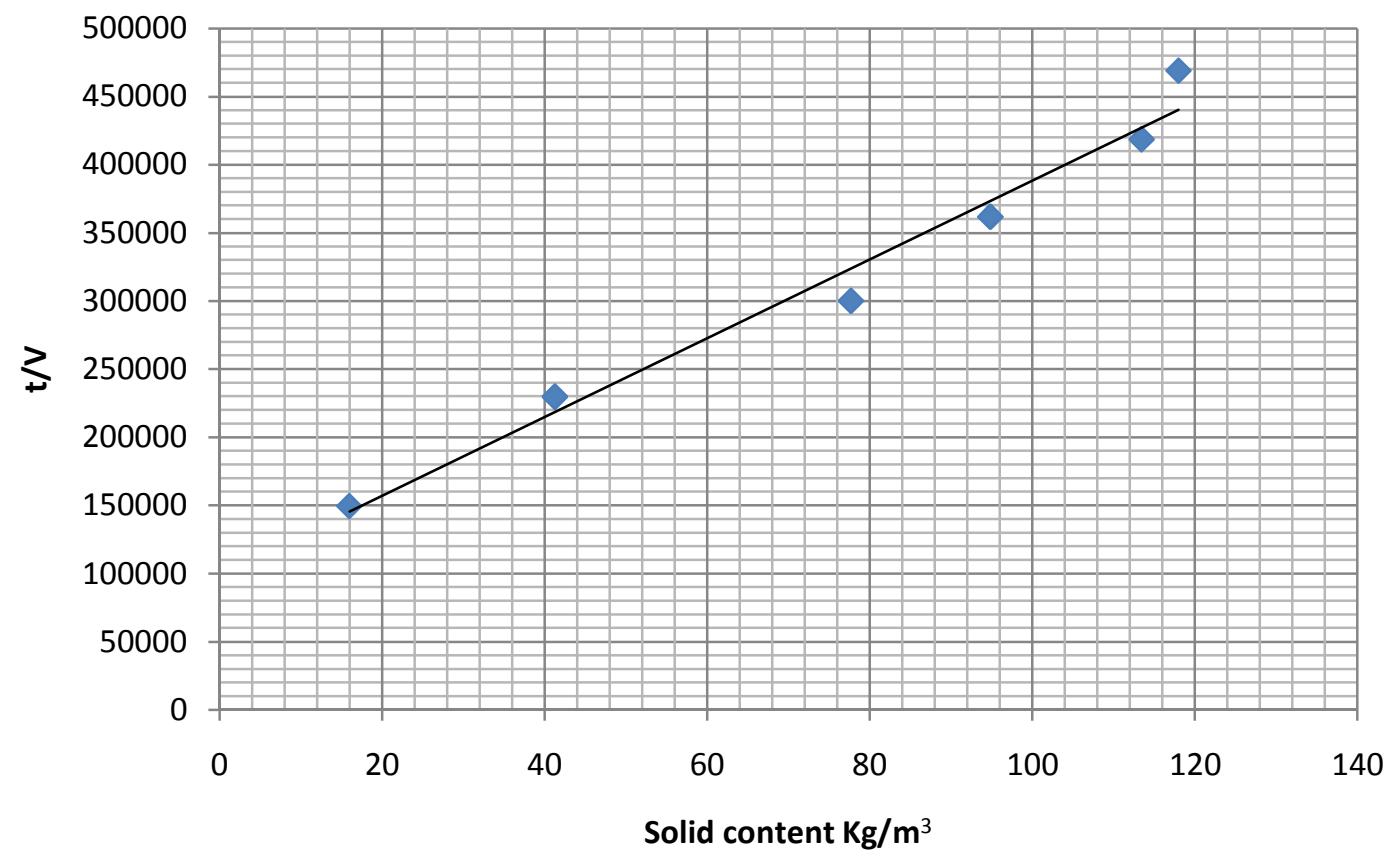

Figure 2 showing the graph of $/ \mathrm{v}$ against solid contents.

Table 2: Filtration of unconditioned sludge, on day one of the experiment.

\begin{tabular}{ccccccc}
\hline Volume $\left(\mathrm{m}^{3}\right)$ & Time $(\mathrm{s})$ & Height of sludge $(\mathrm{m})$ & Hydrostatic pressure $\left(\mathrm{N} / \mathrm{m}^{2}\right)$ & $\mathrm{t} / \mathrm{V}$ & $\mathrm{V}^{2}$ & $\mathrm{~V}^{*} \mathrm{t} / \mathrm{V}$ \\
\hline 0.054729 & 7200 & 0.058 & 566.84 & 131557.31 & 0.002995 & 7200 \\
0.062659 & 14400 & 0.071 & 693.58 & 229815.35 & 0.003926 & 14400 \\
0.071967 & 21600 & 0.079 & 771.62 & 300137.56 & 0.005179 & 21600 \\
0.079592 & 28800 & 0.083 & 810.78 & 361845.41 & 0.006335 & 28800 \\
0.085967 & 36000 & 0.087 & 850.13 & 418765.34 & 0.007390 & 36000 \\
0.092097 & 43200 & 0.100 & 976.85 & 469070.65 & 0.008482 & 43200 \\
0.447011 & & & 778.3 & 1911191.8 & 0.034306 & 151200.1 \\
\hline
\end{tabular}

Initial height $=0.25 \mathrm{~m}$, Area $=0.9 \mathrm{~m}^{2}$, Hydrostatic pressure $=778.3 \mathrm{~N} / \mathrm{m}^{2}$, Dynamic Viscosity $=0.8816 \mathrm{~N} . \mathrm{s} / \mathrm{m}^{2}$, Solid Content $=76.89 \mathrm{~kg} / \mathrm{m}^{3}, \mathrm{R}=0.81716 \times 10^{8}$, Slope $\mathrm{b}=8.787 \times 10^{6}$.

The slope was analyzed by regression,

The specific resistance $\mathrm{R}$ is:

$$
b=\frac{n \sum V\left(\frac{t}{V}\right)-\sum V \sum\left(\frac{t}{V}\right)}{n \sum(V)^{2}-\left(\sum V\right)^{2}}
$$

$$
R=\frac{\rho g h A^{2} V_{s}}{\mu w_{d}}
$$

Table 3: Filtration of unconditioned sludge at 24 hours interval for 5 days.

\begin{tabular}{ccccccc}
\hline Volume $\left(\mathrm{m}^{3}\right)$ & Time $(\mathrm{s})$ & Height of sludge $(\mathrm{m})$ & Hydrostatic pressure $\left(\mathrm{N} / \mathrm{m}^{2}\right)$ & $\mathrm{t} / \mathrm{V}$ & $\mathrm{V}^{2}$ & $\mathrm{~V}^{*} \mathrm{t} / \mathrm{V}$ \\
\hline 0.12666 & 86400 & 0.162 & 1584.32 & 682141.2 & 0.01604 & 86400 \\
0.13186 & 172800 & 0.204 & 1995.83 & 1310480.8 & 0.01739 & 172800 \\
0.13361 & 259200 & 0.206 & 2014.62 & 1939974.6 & 0.01785 & 259200 \\
0.13427 & 345600 & 0.207 & 2023.31 & 2573918.2 & 0.01803 & 345600 \\
0.13516 & 432000 & 0.210 & 2054.53 & 3196211.9 & 0.01827 & 43200 \\
0.66156 & & & 1934.52 & 9702726.7 & 0.08758 & 1296000 \\
\hline
\end{tabular}

Area $=0.9 \mathrm{~m}^{2}$, Hydrostatic pressure $=1934.52 \mathrm{~N} / \mathrm{m}^{2}$, Dynamic Viscosity $=0.9776 \mathrm{~N} . \mathrm{s} / \mathrm{m}^{2}$, Slope $\mathrm{b}=$ $3.053206 \times 10^{8}$, Solid Content $=639.82 \mathrm{~kg} / \mathrm{m}^{3}, \mathrm{R}=7.6488 \times 10^{8} \mathrm{~m} / \mathrm{kg}$. 


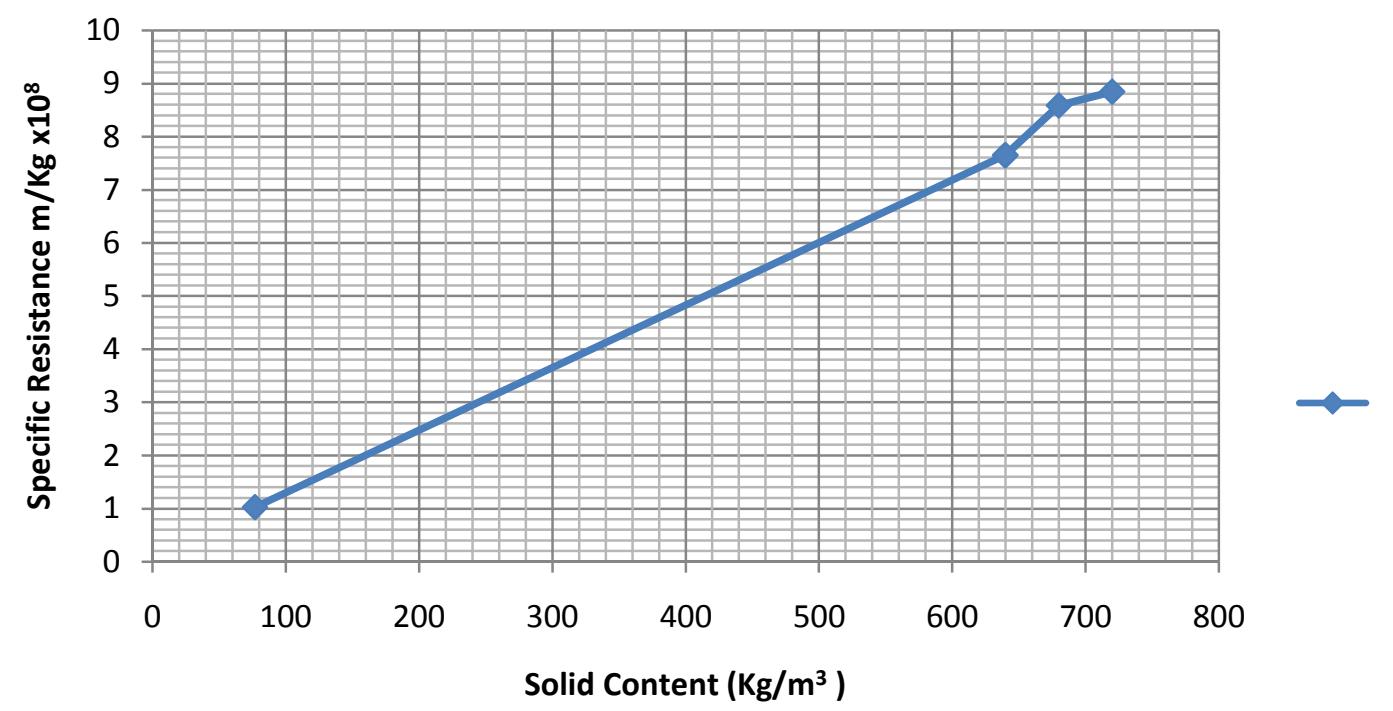

Figure 3: Plot of specific resistance against solid content.

The graphs in Figure 3 shows that the solid content increases as the specific resistance increases, this signifies that as more solid settles the pressure increases and the void ratio decreases and this reduces the volume of filtrate that passes through the cake per time.

Table 4: Effect of ferric chloride on specific resistance of sludge using $10 \mathrm{~g}\left(\mathrm{Fecl}_{3}\right)$ on 10 litres of sludge.

\begin{tabular}{ccccccc}
\hline $\mathrm{s} / \mathrm{N}$ & Time $\mathrm{t}(\mathrm{s})$ & $\begin{array}{c}\text { Volume } \mathrm{V} \\
\left(\mathrm{m}^{3}\right)\end{array}$ & $\mathrm{t} / \mathrm{V}\left(\mathrm{s} / \mathrm{m}^{3}\right)$ & $\mathrm{V}^{2}\left(\mathrm{~m}^{6}\right)$ & $\mathrm{V}^{*} \mathrm{t} / \mathrm{V}(\mathrm{s})$ & $\begin{array}{c}\text { Sludge height } \\
(\mathrm{m})\end{array}$ \\
\hline 1 & 1800 & 0.002025 & 888888.889 & $4.100625 \times 10^{-6}$ & 1800 & 0.020 \\
2 & 3600 & 0.003893 & 924736.707 & $1.515545 \times 10^{-5}$ & 3600 & 0.020 \\
3 & 5400 & 0.005603 & 963769.409 & $3.139361 \times 10^{-5}$ & 5400 & 0.020 \\
4 & 7200 & 0.007133 & 1009392.962 & $5.087969 \times 10^{-5}$ & 7200 & 0.020 \\
5 & 9000 & 0.008003 & 1124578.283 & $6.404801 \times 10^{-5}$ & 9000 & 0.020 \\
& & 0.026657 & 3899266.250 & $1.655774 \times 10^{-4}$ & 27000 & \\
\hline
\end{tabular}

Height of sludge $=0.02 \mathrm{~m}$, Area of filtration $=0.9 \mathrm{~m}^{2}$, Temperature $=27.6^{\circ} \mathrm{C}$, Density $=996.35 \mathrm{Kg} / \mathrm{m}^{3}$, Dynamic viscosity $=0.9031 \mathrm{~N} . \mathrm{s} / \mathrm{m}^{2}$, Hydrostatic pressure $=195.49 \mathrm{~N} / \mathrm{m}^{2}$, Slope $\mathrm{b}=5.87828 \times 10^{7} \mathrm{~S} / \mathrm{m}^{2}, \quad \mathrm{R}=1.2271 \times 10^{8}$ $\mathrm{m} / \mathrm{Kg}$.

Table 5: Effect of ferric chloride on specific resistance of sludge using $20 \mathrm{~g}$ of $\left(\mathrm{Fecl}_{3}\right)$ on 10 litres of sludge.

\begin{tabular}{ccccccc}
\hline $\mathrm{s} / \mathrm{N}$ & Time t $(\mathrm{s})$ & $\begin{array}{c}\text { Volume } \mathrm{V} \\
\left(\mathrm{m}^{3}\right)\end{array}$ & $\mathrm{t} / \mathrm{V}\left(\mathrm{s} / \mathrm{m}^{3}\right)$ & $\mathrm{V}^{2}\left(\mathrm{~m}^{6}\right)$ & $\mathrm{V}^{*} \mathrm{t} / \mathrm{V}(\mathrm{s})$ & $\begin{array}{c}\text { Sludge } \\
\text { height }(\mathrm{m})\end{array}$ \\
\hline 1 & 1800 & 0.002475 & 727272.72 & $6.125625 \times 10^{-6}$ & 1800 & 0.015 \\
2 & 3600 & 0.004763 & 755826.16 & $2.268617 \times 10^{-5}$ & 3600 & 0.015 \\
3 & 5400 & 0.006773 & 797283.33 & $4.587353 \times 10^{-5}$ & 5400 & 0.015 \\
4 & 7200 & 0.008357 & 861553.19 & $6.983945 \times 10^{-5}$ & 7200 & 0.015 \\
5 & 9000 & 0.009332 & 964423.49 & $8.708623 \times 10^{-5}$ & 9000 & 0.015 \\
& & 0.0317 & 4106358.9 & $2.316110 \times 10^{-4}$ & 27000 & 0.015 \\
\hline
\end{tabular}

Height of sludge $=0.015 \mathrm{~m}$, Area of filtration $=0.9 \mathrm{~m}^{2}$, Temperature $=28^{\circ} \mathrm{C}$, Dynamic viscosity $=0.8916 \mathrm{~N} . \mathrm{s} / \mathrm{m}^{2}$, Density $=996.232 \mathrm{Kg} / \mathrm{m}^{3}$, Solid content $=84.0 \mathrm{Kg} / \mathrm{m}^{3}$, Hydrostatic pressure $=146.60 \mathrm{~N} / \mathrm{m}^{2}$, Slope $\mathrm{b}=$ $0.31524 \times 10^{8} \mathrm{~S} / \mathrm{m}^{2}, \mathrm{R}=0.4998 \times 10^{8} \mathrm{~m} / \mathrm{Kg}$. 
Table 6: Effect of ferric chloride on specific resistance of sludge using $30 \mathrm{~g}$ of (Fecl 3 ) on 10 litres of sludge.

\begin{tabular}{ccccccc}
\hline $\mathrm{S} / \mathrm{N}$ & Time t $(\mathrm{s})$ & $\begin{array}{c}\text { Volume } \mathrm{V} \\
\left(\mathrm{m}^{3}\right)\end{array}$ & $\mathrm{t} / \mathrm{V}\left(\mathrm{s} / \mathrm{m}^{3}\right)$ & $\mathrm{V}^{2}\left(\mathrm{~m}^{6}\right)$ & $\mathrm{V}^{*} \mathrm{t} / \mathrm{V}(\mathrm{s})$ & $\begin{array}{c}\text { Sludge height } \\
(\mathrm{m})\end{array}$ \\
\hline 1 & 1800 & 0.0099375 & 181132.08 & $9.875391 \times 10^{-5}$ & 1800 & 0.010 \\
2 & 3600 & 0.0146715 & 245373.68 & $2.152529 \times 10^{-4}$ & 3600 & 0.010 \\
3 & 5400 & 0.017034 & 317013.03 & $2.901572 \times 10^{-4}$ & 5400 & 0.010 \\
4 & 7200 & 0.018534 & 388475.24 & $3.435092 \times 10^{-4}$ & 7200 & 0.010 \\
5 & 9000 & 0.019602 & 459136.82 & $3.842384 \times 10^{-4}$ & 9000 & 0.010 \\
& & 0.079779 & 1591130.85 & $1.331912 \times 10^{-4}$ & 27000 & 0.010 \\
\hline
\end{tabular}

Height of sludge $=0.010 \mathrm{~m}$, Area of filtration $=0.9 \mathrm{~m}^{2}$, Temperature $=29^{\circ} \mathrm{C}$, Density $=995.944 \mathrm{Kg} / \mathrm{m}^{3}$, Dynamic viscosity $=0.8642 \mathrm{~N} . \mathrm{s} / \mathrm{m}^{2}$, Hydrostatic pressure $=97.70 \mathrm{~N} / \mathrm{m}^{2}$, Solid content $=84.0 \mathrm{Kg} / \mathrm{m}^{3}$, Slope $\mathrm{b}=$ $0.27338 \times 10^{8} \mathrm{~s} / \mathrm{m}^{2}, \mathrm{R}=0.29803 \times 10^{8} \mathrm{~m} / \mathrm{Kg}$

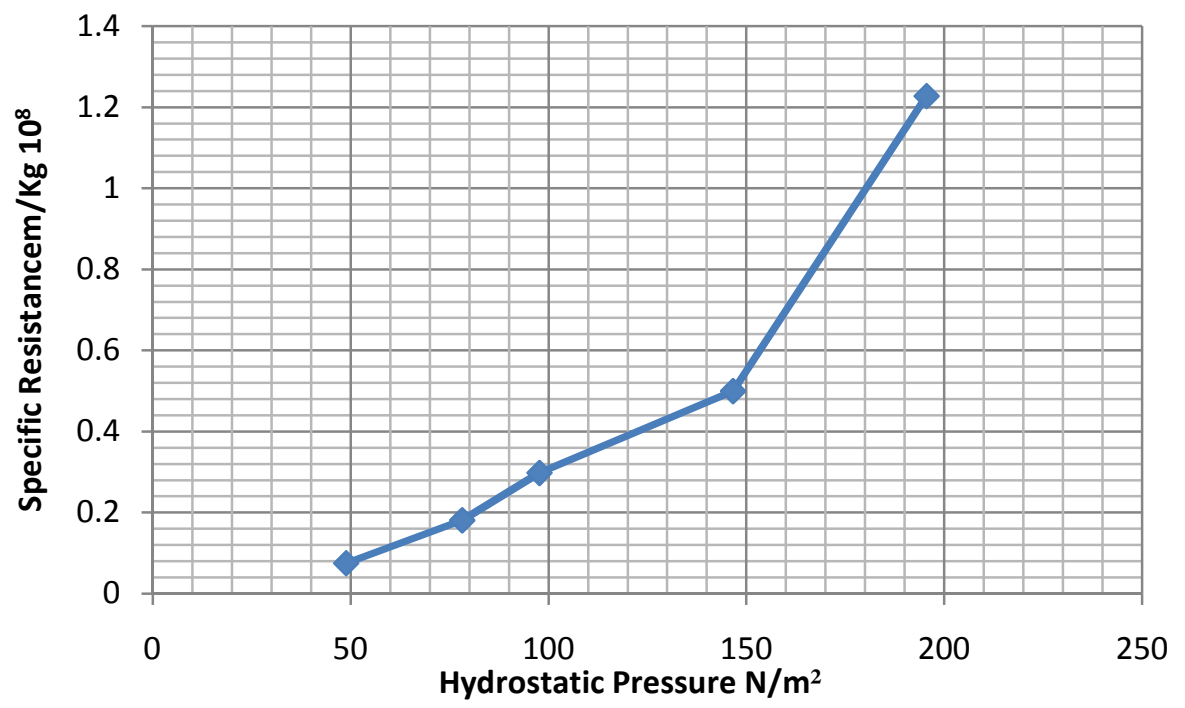

Figure 4, Plot of specific resistance against Hydrostatic pressure.

The derived equation was validated using experimental data from the sewage treatment plant and on verification the theoretical prediction of the derived equation agrees closely with the practical values.

By regression analysis,

Slope is:

$$
\begin{aligned}
& b=\frac{n \sum V\left(\frac{t}{V}\right)-\sum V \sum\left(\frac{t}{V}\right)}{n \sum(V)^{2}-\left(\sum V\right)^{2}} \\
& =\frac{6 x 151200-0.447011 \times 1911191.8}{6 \times 0.034306-0.447011^{2}} \\
& =8.787 \times 10^{6} \mathrm{~s} / \mathrm{m}^{6}
\end{aligned}
$$

Correlation $=0.994$.

Applying,

$$
\begin{aligned}
& \frac{t}{V}=a+b v=-3.285 \times 10^{5} \\
&+V\left(\frac{\mu R w_{d}}{\rho g h A^{2} V_{s}}\right)
\end{aligned}
$$

From the plot of $t / v$ against $\mathrm{V}$,(experimental values from the sewage plant and the theoretical values) it shows that $\mathrm{t} / \mathrm{v}$ increases as the numerical value of $\mathrm{V}$ increases. This is so, since the sludge height in the drying bed decreases as the filtrate volume increases with time.

\begin{tabular}{cccc}
\multicolumn{4}{c}{ Table 7: Experimental data from the sewage plant } \\
\hline Volume $\left(\mathrm{m}^{3}\right)$ & Time $(\mathrm{s})$ & Area $\left(\mathrm{m}^{2}\right)$ & $\mathrm{V}^{2}$ \\
\hline 0.054729 & 7200 & 0.9 & 0.002994 \\
0.062659 & 14400 & 0.9 & 0.003926 \\
0.071967 & 21600 & 0.9 & 0.005179 \\
0.079592 & 28800 & 0.9 & 0.006335 \\
0.085967 & 36000 & 0.9 & 0.007390 \\
0.092097 & 43200 & 0.9 & 0.008482 \\
\hline
\end{tabular}

Table 8: Experimental and Theoretical data

\begin{tabular}{ccc}
\hline $\begin{array}{c}\mathrm{t} / \mathrm{V}\left(\begin{array}{c}\text { Experimental } \\
\text { values) }\end{array}\right. \\
\mathrm{t} / \mathrm{V} \text { (Theoretical } \\
\text { values) }\end{array}$ & Time(s) \\
\hline $1.32 \times 10^{5}$ & $1.53 \times 10^{5}$ & 7200 \\
$2.30 \times 10^{5}$ & $2.22 \times 10^{5}$ & 14400 \\
$3.00 \times 10^{5}$ & $3.04 \times 10^{5}$ & 21600 \\
$3.63 \times 10^{5}$ & $3.71 \times 10^{5}$ & 28800 \\
$4.19 \times 10^{5}$ & $4.27 \times 10^{5}$ & 36000 \\
$4.69 \times 10^{5}$ & $4.81 \times 10^{5}$ & 43200 \\
\hline
\end{tabular}




\section{CONCLUSION}

Natural filtration process that makes use of sand drying bed has been used to propose an equation using dimensional analysis approach. The major parameters that influence filtration processes were incorporated. It was observed from the analysis of experimental data that the derived equation was in accordance with theoretical predictions. The results obtained in investigating the effect of initial solid content, pressure and ferric chloride conditioning on specific resistance show that there was a general decrease in the specific resistance with increasing dilution of ferric chloride dosage. There was also corresponding increase in specific resistance with increased pressure. The ferric chloride dosage that was tested in the following order, $10 \mathrm{~g}, 20 \mathrm{~g}, 30 \mathrm{~g}, 40 \mathrm{~g}$, and $50 \mathrm{~g}$ gave specific resistance values of $1.2271 \mathrm{x}$ $10^{8} \mathrm{~m} / \mathrm{Kg}, \quad 0.4998 \times 10^{8} \mathrm{~m} / \mathrm{Kg}, \quad 0.29803 \times 10^{8} \mathrm{~m} / \mathrm{Kg}$, $0.18124 \times 10^{8} \mathrm{~m} / \mathrm{Kg}, \quad 0.075466 \quad \mathrm{x} \quad 10^{8} \mathrm{~m} / \mathrm{Kg}$ respectively. On verification using experimental data obtained from the sewage plant, the theoretical predictions of the derived equation gave a close relationship with the practical values.

When the results obtained using the derived equation was compared with Carman's equation it showed a similar trend among the parameters verified.

All these results are in agreement with previous work and as a result, specific resistance can be used to quantify sludge filterability. The derived equation can be accepted in sludge dewatering process since it is in agreement with previous research

\section{RECOMENDATIONS}

Sludge drying bed should be provided with cover like the one in use in 'green house effect' to make it functional throughout the year since its efficiency is dependent on weather and climate condition. Sludges should be pre- treated with conditioners to facilitate the filterability of the sludge.

\section{REFERENCES}

[1] Alfa, M.I., Otun, J.A., Igboro, S.B., Dahunsi, S.O., Ajayi, S.A., Akali, D.M, "Between and Betwixt Soil Fertility Improvement and Disease Transmission; An Assessment of the Suitability of Anaerobic Digestion Effluent for Direct Application as Fertilizer". Nigerian Journal of Technology, Vol. 32, No 3 2013, pp 492-497.
[2] Clarke, J.W., Viessman, W ,Jr. and Hammer, M.J. "Water Supply and Pollution Control" Harper and row publishers, $3^{\text {rd }}$ edition, New York, 1977.

[3] Mikkelsen, L.H and Keiding, K. "Physiochemical Characteristics of Full Sewage Sludge with implication to Dewatering" Water Research, Vol. 36, No.10, 2002 pp.2451-2462.

[4] Echenfelder, W.Jr. and Santhanam, C.J. "Sludge Treatment", Marcel Sehker Inc. New York, 1981.

[5] Mehrdadi, N, Joshi, S.G, Nasrabi, T and Hoveidi, H."Application of solar energy for drying sludge from pharmaceutical industrial wastewater and probable use", International Journal, Environmental Resources vol. 1 no 1, 2006, pp 42-48.

[6] Rajput, R. K.," Fluid Mechanics and Hydraulic Machines". S. Chand and Company Ltd; $3^{\text {rd }}$ edition Ram Nagar, New Delhi, 2004.

[7] Ademiluyi, J.O., Anazodo, U.G.N, and Egbuniwe, N. "Filtrability and Compressibility of Sludge, Conclusion". Effluent and Water Treatment Journal Vol. 23 No. 1, 1983, p.25.

[8] Agunwamba, J .C. “Waste Engineering Management Tools". Immaculate Publication Ltd; Ogui Enugu, 2001.

[9] Carman, P. C. "A Study of the Mechanism of filtration Part II", Journal of the Society of Chemical Industry, Transactions and Communications Vol. 53 No.9, 1934b, pp.301T- 309T.

[12] Hass, C.N and Vamos, R.J, "Hazardous and industrial waste treatment", Prentice Hall, Englewood Cliffs, New Jessey, 1995, PP 75-78.

[13] Ruth, B.E."Studies in Filtration- Derivation of General Filtration Equation" Industrial and Engineering Chemistry Journal.Vol.27, no 6, 1935, pp 708-723.

[14] Coackley, P. "Laboratory scale filtration experiment and their application to sewage and industrial waste", Reinhold pub. corp, New York, 1958, pp 270-290.

[15] Anazodo, U .G. N. "Dimensional Equation for Sludge Filtration". Effluent and Water Treatment Journal Vol. 14 No. 9, 1974, pp.517- 523.

[16] White, M.J., and Gale, R.S., "Comments on Dimensional Equation for Sludge Filtration". Effluent and Water Treatment Journal, Vol.15 no 8, 1975, pp.422-423.

[17] Ademiluyi,J.O., Egbuniwe, N. and Agunwamba, J.C. "A Dimensionless Number as an Index of Sludge Dewaterability". Journal of Engineering for Developmentvol.1, No. 1, 1987 pp 1-9 